\title{
Olfactory eavesdropping between two competing stingless bee species
}

\author{
Elinor M. Lichtenberg • Michael Hrncir • \\ Izabel C. Turatti • James C. Nieh
}

Received: 13 September 2010 /Revised: 20 September 2010 / Accepted: 4 October 2010/Published online: 18 November 2010

(C) The Author(s) 2010. This article is published with open access at Springerlink.com

\begin{abstract}
Foragers can improve search efficiency, and ultimately fitness, by using social information: cues and signals produced by other animals that indicate food location or quality. Social information use has been well studied in predator-prey systems, but its functioning within a trophic level remains poorly understood. Eavesdropping, use of signals by unintended recipients, is of particular interest because eavesdroppers may exert selective pressure on signaling systems. We provide the most complete study to date of eavesdropping between two
\end{abstract}

Communicated by M. Beekman

Electronic supplementary material The online version of this article (doi:10.1007/s00265-010-1080-3) contains supplementary material, which is available to authorized users.

E. M. Lichtenberg $(\bowtie) \cdot$ J. C. Nieh

Division of Biological Sciences,

University of California, San Diego,

9500 Gilman Drive MC 0116,

La Jolla, CA 92093-0116, USA

e-mail: elichten@ucsd.edu

\section{Hrncir}

Departamento de Biologia, Faculdade de Filosofia,

Ciências e Letras de Ribeirão Preto, Universidade de São Paulo,

Bloco 7, Avenida Bandeirantes 3900,

Ribeirão Preto, 14040-901 São Paulo, Brazil

\section{Hrncir}

Departamento de Ciências Animais,

Universidade Federal Rural do Semi-Árido,

Av. Francisco Mota, 572,

Mossoró, 59.625-900 Rio Grande do Norte, Brazil

I. C. Turatti

Departamento de Física e Química,

Faculdade de Ciências Farmacêuticas de Ribeirão Preto,

Universidade de São Paulo,

Avenida do Café $\mathrm{s} / \mathrm{n}$,

Ribeirão Preto, 14040-903 São Paulo, Brazil competing social insect species by determining the glandular source and composition of a recruitment pheromone, and by examining reciprocal heterospecific responses to this signal. We tested eavesdropping between Trigona hyalinata and Trigona spinipes, two stingless bee species that compete for floral resources, exhibit a clear dominance hierarchy and recruit nestmates to high-quality food sources via pheromone trails. Gas chromatography-mass spectrometry of $T$. hyalinata recruitment pheromone revealed six carboxylic esters, the most common of which is octyl octanoate, the major component of $T$. spinipes recruitment pheromone. We demonstrate heterospecific detection of recruitment pheromones, which can influence heterospecific and conspecific scout orientation. Unexpectedly, the dominant $T$. hyalinata avoided $T$. spinipes pheromone in preference tests, while the subordinate T. spinipes showed neither attraction to nor avoidance of $T$. hyalinata pheromone. We suggest that stingless bees may seek to avoid conflict through their eavesdropping behavior, incorporating expected costs associated with a choice into the decision-making process.

Keywords Social information · Interceptive eavesdropping · Decision making · Dominance · Foraging . Cephalic labial glands

Abbreviations
$\begin{array}{ll}\text { GC-MS } & \text { Gas chromatography-mass spectrometry } \\ \text { LGE } & \text { Labial gland extract } \\ w / w & \text { Weight/weight }\end{array}$

\section{Introduction}

Animals at multiple trophic levels actively search for patchily distributed food such as mobile prey, flowering 
or fruiting trees, or carrion. Such consumers can improve search efficiency, and ultimately fitness, by using information provided by the food itself or other organisms in the vicinity (Giraldeau 1997; Dornhaus and Chittka 2004). Use of social information (sensu Danchin et al. 2004) by foragers appears to be widespread. Information can come from signals (features or behaviors that have evolved to alter the behavior of the receiver in a specific way) or cues, which did not evolve because of such effects (Maynard Smith and Harper 2003). When signals provide such information, unintended receivers that use it are exhibiting "interceptive eavesdropping." Because signals evolve through selection for information flow, they are vulnerable to selective pressures exerted by eavesdroppers (Peake 2005). Evolutionary and ecological effects of eavesdropping may be particularly strong and diverse in the context of foraging because resultant increases in food discovery efficiency cascade through food webs (Kean et al. 2003). Many examples show predators and prey benefiting from social information to locate prey and avoid predators, respectively (e.g., sources in Stowe et al. 1995; Peake 2005; Seppänen et al. 2007; Valone 2007). However, social information can also improve search efficiency within a trophic level. In this latter context, heterospecific eavesdropping (on signals) and "spying" (using social information provided by cues; Wisenden and Stacey 2005) can affect community structure. Such strategies can (1) increase the frequency of interaction among competitors (Seppänen et al. 2007) or (2) drive the formation and maintenance of foraging groups (Goodale et al. 2010) that provide benefits (e.g., protection) that overcome costs of food sharing (Stevens and Gilby 2004).

Despite the ecological implications of eavesdropping, little is known about how dominant and subordinate species competing for food use social information. To date, only a handful of studies have investigated interceptive eavesdropping on food location or quality signals by heterospecifics. Exploitation of heterospecific food location cues has also received some attention, primarily with social insects. Experiments suggest that subordinate species can avoid competitors (e.g., Pimm et al. 1985; Fletcher 2008; Evans et al. 2009; Slaa and Hughes 2009) or depleted resources (e.g., Nakashima et al. 2002; Yokoi et al. 2007) by using heterospecific visitation signals and cues. This latter phenomenon may be quite sophisticated; bumble bees can learn to be attracted or repelled by social information depending on their past experience with the food source, use it to determine when flowers replenish their nectar, and increase rejection of visited flowers when the visitor was an aggressive species. Avoidance of depleted resources through detection of chemical or visual cues likely saves bees time (Goulson 2009), thereby increasing foraging efficiency. Dominant species, on the other hand, are sometimes attracted to food cues and signals of heterospecific competitors (reviewed in Slaa and Hughes 2009; Goodale et al. 2010). This diversity of responses suggests the rules governing eavesdropping and spying within a trophic level are more complex than in predator-prey situations and require more sophisticated decision making (Coolen et al. 2003). To understand these rules, and the effects of social information on communities and signaling systems, we must further investigate within-trophic-level eavesdropping and spying across a range of species.

Highly social insects are an excellent system for studying eavesdropping and spying by competitors. Species often compete for food with sympatric relatives (Hubbell and Johnson 1977; Hölldobler and Wilson 1990; Eltz et al. 2002) and exhibit clear dominant-subordinate relationships (e.g., Fellers 1987; Lichtenberg et al. 2010). Social insects combine excellent associative learning (Dukas 2008) with powerful olfactory detection (Greenfield 2002) for successful foraging. Using social information may thus provide fitness benefits through improved search efficiency. Both ants and several genera of eusocial stingless bees (Apidae, Meliponini) recruit nestmates by depositing attractive pheromones at a high-quality food source or as a trail between food and nest (Hölldobler and Wilson 1990; Nieh 2004). Because recruitment pheromones are signals present in the public domain, they are susceptible to eavesdropping. Stingless bee trails may be particularly at risk because the trails are much less heavily guarded than are ant foraging trails (EML, personal observation). Where ant eavesdropping has been observed, it is typically between parabiotic "garden ant" species that share nests in epiphytes and thus are highly likely to encounter each others' trails (Slaa and Hughes 2009).

Research shows that both intra- (Boogert et al. 2006; Jarau 2009) and interspecific (Nieh et al. 2004a) eavesdropping occurs in stingless bees. Coupled with patterns of response to the visual presence of heterospecifics on flowers (Slaa et al. 2003) and anecdotal observations (Kerr et al. 1963; Johnson and Hubbell 1975; Johnson 1983), these studies suggest that stingless bees actively avoid food sources of decreased resource quality or to which they will have limited access. In particular, stingless bees appear to avoid resources occupied by dominant species, thereby steering clear of conflict (the dominance motivation hypothesis). Dominant species may also benefit by following subordinates' pheromone trails, using this social information to discover high-quality food sources that they can take over. Because stingless bees serve as major pollinators of tropical plants (Endress 1994), eavesdropping interactions between sympatric colonies may significantly affect bees' foraging patterns and, ultimately, plant gene flow.

Here, we tested olfactory eavesdropping between two trail-laying stingless bee species that have a clear domi- 
nance relationship. Trigona hyalinata and Trigona spinipes overlap in distribution (Camargo and Pedro 2007), exhibit similar floral utilization (Lichtenberg et al. 2010; unpublished data), and likely compete for resources. Both species use odor trails to recruit large numbers of nestmates to rich resources such as mass-flowering trees and sucrose feeders (Nieh et al. 2003; Nieh et al. 2004b). Trigona hyalinata foragers easily displace $T$. spinipes from food sources (Lichtenberg et al. 2010), both by arriving at a food source en masse and by attacking individual $T$. spinipes foragers (see Supplemental movies). In T. spinipes and all other trail-laying stingless bee species studied to date, recruitment pheromones come from the cephalic labial glands (Jarau 2009). An eavesdropper must both detect the target pheromone and distinguish it from its own. To show that eavesdropping is possible between these two species, we determined the chemical composition and attractiveness to nestmates of $T$. hyalinata labial gland secretions. The pheromone of $T$. spinipes is already known to have one main component: octyl octanoate (Schorkopf et al. 2007). We then tested eavesdropping between these species with preference tests. Under the dominance motivation hypothesis, we predicted that the subordinate T. spinipes (Lichtenberg et al. 2010) would avoid T. hyalinata recruitment pheromone, while the dominant $T$. hyalinata would be attracted to $T$. spinipes pheromone.

\section{Materials and methods}

Study site and colonies

We conducted research at the Universidade de São Paulo, Ribeirão Preto, in southeastern Brazil. This site is in the cerrado ecoregion and provides suitable stingless bee habitat in an otherwise urban and agricultural landscape. Multiple colonies of both $T$. hyalinata and $T$. spinipes inhabit the campus, although only a few colonies were accessible for experimentation because both species tend to nest close to the crowns of trees. We tested eavesdropping between two heterospecific colony pairs that were $100 \mathrm{~m}$ (2008 field season) and $500 \mathrm{~m}$ (2009) apart, and thus within flight range of each other (Kerr 1959). Only these four colonies could be paired with heterospecific colonies within flight range and were sufficiently low to the ground $(<10 \mathrm{~m})$ to allow us to train foragers to feeders.

Bees were trained to visit a training feeder located 10 $15 \mathrm{~m}$ from their nest (exact distance depended on topography) and providing $15 \%$ weight/weight $(w / w)$ sucrose solution $(0.46 \mathrm{M})$. One $T$. hyalinata colony was less motivated to visit the feeder and thus was fed $30 \% w / w(0.99 \mathrm{M})$ sucrose solution. Stingless bees are known to collect nectar ranging from $5 \%$ to $67 \% \mathrm{w} / \mathrm{w}$ sugar, with an average nectar quality of $41 \%$ (Roubik et al. 1995). We used the relatively weak $15 \%$ sucrose solution, which limits overly intense recruitment, because each colony was visiting feeders for at least a month and we did not want nests to become filled with stored honey. To train bees, we placed cotton saturated with sucrose solution at the nest entrance. When necessary, we used a pole and climbed a ladder or the tree to do this. Once bees began feeding on the sucrose solution, we gradually moved the cotton away from the nest entrance and to the final location, ensuring bees followed each move. At the training location, we transferred bees from cotton to feeders. Each feeder consisted of a small inverted jar on a grooved plastic plate (von Frisch 1967). This design provides a constant supply of sucrose solution. Feeders were supported on plastic horizontal surfaces attached to the top of tripods approximately $1 \mathrm{~m}$ high. Before each trial, we let bees recruit to their training feeder until there were sufficient foragers (typically 50-200) for meaningful data collection (see below).

\section{Recruitment pheromone chemical analysis}

We determined the chemical composition of $T$. hyalinata recruitment pheromone via gas chromatography-mass spectrometry (GC-MS). We dissected labial glands from five foragers from the nest used in 2009 under a stereo microscope, carefully separating the glands from all other tissues. All glands were combined in $300 \mu \mathrm{L}$ pure hexane (Labsynth) and dissolved at room temperature for $24 \mathrm{~h}$ before being stored in a freezer. To prevent contamination from alarm pheromone or other substances on the bees' cuticles, we rinsed bees five times in hexane before dissection.

We carried out the GC-MS with a Shimadzu QP-2010 GCMS system. The GC was equipped with two different columns: first a DB-5MS $(30 \mathrm{~m} \times 0.25 \mathrm{~mm}, \mathrm{~J} \& W$ Scientific, Folsom, CA, USA) and then a more polar DB-WAX column $(30 \mathrm{~m} \times 0.25 \mathrm{~mm}, \mathrm{~J} \& \mathrm{~W}$ Scientific) for better separation of similar-weight compounds. Helium was used as a carrier gas (constant linear flow rate $40.0 \mathrm{~cm} / \mathrm{s}$ with the DB-5MS column, $39.7 \mathrm{~cm} / \mathrm{s}$ with the DB-WAX column). With the DB-5MS column, temperature was held at $50^{\circ} \mathrm{C}$ for $5 \mathrm{~min}$, then increased by $5^{\circ} / \mathrm{min}$ to $300^{\circ} \mathrm{C}$, where it was held for the final $5 \mathrm{~min}$. With the DB-WAX column, temperature started at $50^{\circ} \mathrm{C}$, then increased by $3 \% \mathrm{~min}$ to $240^{\circ} \mathrm{C}$, where it was held for the final $5 \mathrm{~min}$. We made preliminary compound identifications using the Wiley mass spectral library (Mclafferty 2000), then confirmed all identifications with synthetic standards. Analytical standards' sources were: Sigma-Aldrich Corp. (St. Louis, MO, USA), hexyl octanoate and octyl octanoate; CTC Organics (Atlanta, GA, USA), octyl decanoate; Jocelyn Millar (Riverside, CA, USA), octyl hexanoate; Stefan Jarau (Ulm, Germany), decyl hexanoate and hexyl decanoate. 


\section{Preference tests}

We assessed bees' responses to con- and heterospecific recruitment pheromones via preference tests, where individuals chose between two feeders each bearing different odors. Before the start of a trial we covered the training feeder, which encouraged bees to search for alternate food sources. Thus, participating bees functioned as scouts, individuals using internal information (knowledge of food types, sensory input, etc.) to locate food sources previously unknown to them (Biesmeijer and de Vries 2001). Preference tests were conducted 20-25 m from the nest and 15-20 $\mathrm{m}$ from the training feeder (see Fig. 1). Because bees scout independently and the potential search area increases with distance from the training feeder, new feeders farther from the training feeder will be found more slowly. Thus, we chose distances at which bees would arrive singly, yet frequently enough to gather meaningful data (at least ten decisions) during a trial. We chose a 15min trial duration, within the 20-min retention time found for $T$. spinipes recruitment pheromone (Nieh et al. 2004b). Training feeders were set out when bees became active in the morning (c. 0900 hours) and trials continued through mid-day. Because the effects of low humidity on recruitment pheromone and bee scouting behavior are unknown, we conducted trials only when the relative humidity was above 50\%. Only one colony was tested each day, participating in one to four trials of the various types described below. Solvent control and the treatment trials were interspersed.

At the testing location, we set up two feeders with $40 \mathrm{~cm}$ between their centers. This distance was short enough that arriving bees could smell both feeders and allowed simultaneous observation by a single observer. Recruitment pheromones have an active space of approximately $20 \mathrm{~m}$ under calm conditions (D. Schorkopf, personal communication). Preliminary trials showed $40 \mathrm{~cm}$ was far enough that bees would distinguish between the two feeders and treat them as separate odor sources. Bees arriving at the test location made a choice by landing on one of the two testing

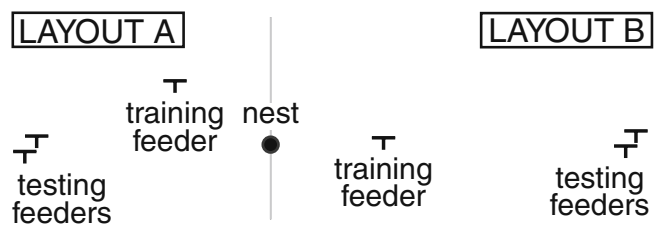

Fig. 1 General layout of feeders during preference tests. Layout and exact locations used depended on topography, avoiding dense vegetation, steep slopes, roads, buildings, etc. Distances were: nest to training feeder $10-15 \mathrm{~m}$, training feeder to testing feeders $15-20 \mathrm{~m}$, nest to testing feeders $20-25 \mathrm{~m}$, between the center of each testing feeder $40 \mathrm{~cm}$ feeders. To avoid any potentially confounding effect of food presence, these feeders were empty. We immediately removed bees once they made a choice to eliminate visual local enhancement: orientation of foragers to the visual presence of other bees (Slaa et al. 2003). These bees were marked with enamel paint, released, and not counted in subsequent trials to avoid pseudoreplication.

\section{Pheromones}

Recruitment pheromone sources were (1) fresh pheromone and (2) labial gland extract (LGE). To collect fresh pheromone, we trained one forager of the marking species to visit a feeder with $30 \%$ or $45 \%$ (1.5 M) sucrose solution (using the higher concentration when recent recruitment levels were low) approximately $10-20 \mathrm{~m}$ further from the nest than the training feeder. This feeder bore strips of paper upon which bees readily deposited pheromone by rubbing their mouthparts on the paper's edge while running along it. An odor mark was defined as one such rubbing event. Once the trained bee was observed odor marking and a group of recruits arrived at the feeder (indicating strong recruitment, and corresponding to the "pulses" in Nieh et al. 2004b), we harvested pheromone. We cut off the three to five strips of paper upon which bees had spent the most time odor marking, yielding seven to ten recent marks. The papers were then quickly transported (approximately $2 \mathrm{~min}$ in 2008, $10 \mathrm{~min}$ in 2009) to the other species' testing location. In 2009, when the two nests were farther apart, we stored the marked papers in a clean glass vial in a cooled container during transport to slow volatilization. These strips were placed in a slit on the platform supporting one of the testing feeders. Clean paper was placed in a slit on the other feeder.

Use of LGE facilitates the application of precise, reliable pheromone doses and yields the same orientation behaviors as naturally deposited pheromone in the three Trigona species previously tested (Jarau 2009). We prepared LGE in a manner similar to the sample prepared for chemical analysis, except that each bee's glands were separately dissolved in $100 \mu \mathrm{L}$ of hexane. For LGE trials, we attached a small strip of filter paper $(20 \times 5 \mathrm{~mm})$ to each testing feeder. In solvent control trials testing the effect of hexane, one randomly selected strip remained dry while the other bore $10 \mu \mathrm{L}$ of hexane. For the treatments described below, we applied $10 \mu \mathrm{L}$ of LGE to one of the filter paper strips. Ten microliters equaled 0.1 bee equivalents, a concentration to which closely related species respond (Jarau et al. 2004). One bee equivalent is the full labial gland content from one bee. In intraspecific preference tests, we used LGE harvested from the colony being tested. Each replicate trial used LGE from a different individual. We verified that bees' responses to LGE matched behavior exhibited 
towards fresh pheromone. All equipment was cleaned with lab detergent or ethanol between trials.

Recruitment pheromone glandular source-intraspecific preference tests

T. spinipes produces recruitment pheromone in the cephalic labial glands and will follow an artificial trail made from labial gland extract (Schorkopf et al. 2007). In intraspecific preference tests, we determined whether $T$. hyalinata cephalic labial gland secretions are attractive to T. hyalinata. We compared bees' responses to LGE from nestmates to responses in solvent control trials, repeating treatment and control five times per colony. We also tested T. spinipes in order to have a common methodology for comparing bees' responses to nestmate recruitment pheromone with the eavesdropping responses described below. The two colonies of each species used in the eavesdropping experiment were also used for this one.

\section{Interspecific eavesdropping}

We used preference tests to determine heterospecific eavesdropping responses between $T$. hyalinata and $T$. spinipes under two conditions: (1) In the one-pheromone treatment, bees chose between a dry strip of paper and paper with $10 \mu \mathrm{L}$ of heterospecific LGE (five trials per colony) or between a dry strip of paper and freshly deposited heterospecific pheromone (two to three trials per colony). To test the generality of eavesdropping responses, we conducted two additional one-pheromone trials per colony using LGE from bees captured from a different location (approximately 500-1,000 m away). These latter bees were likely from a different colony, and may or may not have been encountered by test colony foragers before experimentation. (2) In the two-pheromone treatment, bees chose between nestmate LGE and heterospecific LGE (five trials per colony).

Data analysis

For each trial, we determined the proportion of bees landing on the feeder with hexane (solvent control trials), the feeder with nestmate LGE (intraspecific preference tests) or the feeder with heterospecific LGE (eavesdropping trials). All proportions were transformed using Anscombe's arcsine transformation (Zar 1999) to meet parametric assumptions. We assessed responses to nestmate pheromone and eavesdropping with two-factor ANOVAs, including colony as a fixed effect. For each species, we conducted five separate analyses, corresponding to separate questions (see Table 1). (A1) Did the average proportion of bees preferring the feeder with nestmate LGE in intraspecific preference tests differ from the proportion that preferred the hexane feeder in solvent control trials? This tested whether the labial glands are a source of recruitment pheromone. (A2) In the one-pheromone treatment, did bees show the same eavesdropping response to heterospecific LGE and fresh heterospecific pheromone? Due to the small number of trials with fresh pheromone, we used the non-parametric Mann-Whitney $U$ test and untransformed proportions for this analysis. (A3) Did bees respond the same to heterospecific LGE from a nearby and a more distant heterospecific colony? This analysis employed KruskalWallis tests and untransformed proportions due to the small number of trials with the distant colonies. (A4) Was there a difference in the average proportion of bees preferring hexane in solvent control trials, heterospecific LGE in the one-pheromone eavesdropping treatment or heterospecific LGE in the two-pheromone treatment? This tested heterospecific eavesdropping responses and was followed by a Tukey HSD test to determine pairwise significant differences

Table 1 Behavioral questions addressed in this study

Question

(A2) Eavesdropping on heterospecific labial gland extract (LGE)

(A3) Response to labial gland extracts from different heterospecific colonies

(A4) Eavesdropping on heterospecific recruitment pheromone

(A5) Response to own recruitment pheromone in the presence or
(A1) Recruitment pheromone glandular source vs. natural odor marks absence of heterospecific pheromone

Treatments compared

Solvent control
Nestmate LGE
One-pheromone treatment
Fresh odor marks
One-pheromone treatment, nearby colony
One-pheromone treatment, distant colony
Solvent control
One-pheromone treatment
Two-pheromone treatment
Nestmate LGE
Two-pheromone treatment (proportion in
opposite direction of A4 analysis)

See text for treatment descriptions 
if the overall test was significant. (A5) Did the average proportion of bees landing on the feeder with nestmate LGE differ between intraspecific preference tests and the twopheromone eavesdropping treatment? This tested whether the presence of heterospecific LGE affects bees' preference for their own recruitment pheromone. Interaction terms were removed from all analyses because they were not statistically significant. Analyses were conducted in R v. 2.9.2. Table 2 shows the number of trials conducted for each treatment and the numbers of bees participating in each trial.

\section{Results}

Recruitment pheromone chemical analysis

T. hyalinata labial gland extract contained six major components, all carboxylic esters (Fig. 2, Table 3). Octyl octanoate, the major component of $T$. spinipes recruitment pheromone (Schorkopf et al. 2007), was the most abundant component of $T$. hyalinata recruitment pheromone.

Recruitment pheromone glandular source - intraspecific preference tests (question A1)

T. hyalinata LGE was highly attractive to conspecifics, strongly suggesting it is the source gland of recruitment

Table 2 Sample sizes and bee participation for each of the treatments, separated by species

\begin{tabular}{lll}
\hline Treatment & $\begin{array}{l}\text { Number } \\
\text { of trials } \\
\text { conducted }\end{array}$ & $\begin{array}{l}\text { Mean number of } \\
\text { bees choosing a } \\
\text { feeder (min, max) }\end{array}$ \\
\hline $\begin{array}{l}\text { Trigona hyalinata } \\
\text { Solvent control }\end{array}$ & 10 & $20.6(10,38)$ \\
Nestmate LGE & 11 & $21.2(13,28)$ \\
One-pheromone treatment & & $18.4(11,26)$ \\
Nearby colony & 9 & $15.3(12,18)$ \\
Distant colony & 4 & $14.8(5,24)$ \\
Fresh odor marks & 4 & $18.4(11,32)$ \\
Two-pheromone treatment & 11 & $20.6(10,49)$ \\
Trigona spinipes & & $19.7(11,34)$ \\
Solvent control & 8 & $17.2(10,29)$ \\
Nestmate LGE & 10 & $14.4(10,19)$ \\
One-pheromone treatment & & $17.7(12,30)$ \\
Nearby colony & 10 & $17.5(12,25)$ \\
Distant colony & 5 & 6
\end{tabular}

The fresh odor marks trial with only five bees was included because death of the marking colony prevented us from repeating that trial pheromone for this species. Compared to their responses to hexane in solvent control trials, foragers of each species chose a feeder with nestmate LGE significantly more often than a paired feeder with no odor (A1; Fig. 3; Table 4). Preferences did not differ between conspecific colonies (Table 4). The T. spinipes nest we used in 2008 fell from its host tree and died before we completed our experiment, so we were only able to conduct three solvent control trials with this colony.

Interspecific eavesdropping (questions $\mathrm{A} 2-\mathrm{A} 4$ )

For both species, response to heterospecific recruitment pheromone did not vary with pheromone source (A2, fresh pheromone vs. LGE: $T$. hyalinata, $29 \%$ vs. $34 \%, U_{17}=34$, $p=0.39 ;$ T. spinipes, $52 \%$ vs. $\left.51 \%, U_{19}=39, p=0.67\right)$, the identity of the colony donating the LGE (A3, nearby vs. far: T. hyalinata, $37 \%$ vs. $29 \%, K_{3}=3.84, p=0.28 ;$ T spinipes, $51 \%$ vs. $53 \%, K_{3}=0.62, p=0.89$ ), or the colony being tested (ANOVA results in Table 4). Compared to solvent control trials, $T$. hyalinata strongly avoided $T$. spinipes recruitment pheromone (A4; Fig. 4; Table 4) in both one- and twopheromone treatments. When choosing between conspecific and heterospecific LGE, the same proportion of $T$. hyalinata foragers preferred their own pheromone as in intraspecific preference tests (A5; Fig. 5; Table 4). Trigona spinipes foragers' response to T. hyalinata pheromone was the same as their response to hexane (A4; Fig. 4; Table 4). Although T. spinipes foragers appeared to choose the feeder with $T$. hyalinata LGE less frequently in the twopheromone treatment than in the one-pheromone treatment, this difference was not statistically significant $(p=0.06)$. However, the presence of T. hyalinata pheromone significantly reduced $T$. spinipes preference for their own LGE (A5; Fig. 5; Table 4).

\section{Discussion}

Recent evidence suggests that social information use by foragers is widespread, but our understanding of how animals use such information remains limited. Most examples of interceptive eavesdropping and "spying" occur between trophic levels or emphasize copying behavior (reviewed in Dall et al. 2005; Peake 2005; Seppänen et al. 2007; Valone 2007; Goodale et al. 2010). Our results provide the most complete example to date of interceptive eavesdropping by competing social insects: we determined the composition and probable glandular source of the chemical signal, and examined reciprocal heterospecific responses to this signal in preference tests with multiple colonies. We show heterospecific avoidance eavesdropping by a stingless bee: $T$. hyalinata avoids the recruitment 
Fig. 2 Gas chromatograph of $T$. hyalinata labial gland secretions (DB-WAX column). Each letter corresponds to one peak (component). Names and details of the chemical components are given in Table 2

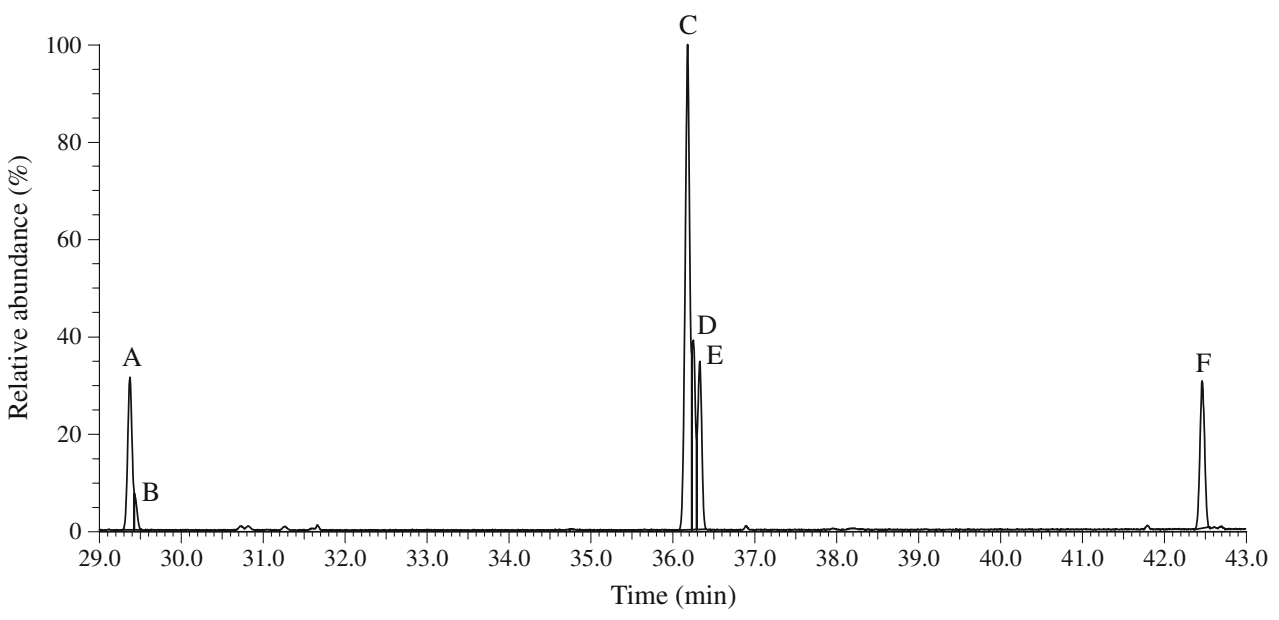

pheromone of T. spinipes. Among pollinating social bees, this within-trophic-level social information can help foragers avoid unprofitable resources or conflict (e.g., Stout et al. 1998; Nieh et al. 2004a).

Chemical analysis of T. hyalinata and T. spinipes LGE demonstrates that the pheromones should be (1) detectable by both species because both contain octyl octanoate in relatively high concentrations and (2) differentiable because T. spinipes recruitment pheromone consists of one major component while T. hyalinata has six (Fig. 2). One of these, hexyl octanoate, is reported for the first time as a component of stingless bee recruitment pheromones. Unlike the pattern reported for other social insects (Slaa and Hughes 2009), eavesdropping responses did not depend on relative dominance of the eavesdropping and signaling species. In our study, the dominant species, T. hyalinata, avoided the recruitment pheromone of the subordinate species. Trigona spinipes showed no attraction to or avoidance of the dominant species' pheromone. Under the dominance motivation hypothesis, if eavesdropping decisions were based solely on relative dominance, we would have seen attraction by $T$. hyalinata foragers and avoidance by $T$. spinipes foragers to heterospecific recruitment pheromone.

\section{Recruitment pheromones}

Four trail-laying stingless bee species (in three genera), in addition to our study species, are attracted to labial gland secretions (Jarau 2009; Stangler et al. 2009). These results, taken with the identical chemistry of $T$. spinipes LGE and odor marks (Schorkopf et al. 2007), indicate that stingless bees' recruitment pheromones are secreted by the labial glands. Our finding that $T$. hyalinata foragers are strongly attracted to nestmate LGE, and chemical similarity with congeners' LGEs, strongly suggests that recruitment pheromone comes from the labial glands in this species as well.

Trigona hyalinata recruitment pheromone composition is consistent with recruitment pheromones of congeners (Jarau 2009) and other odor-marking stingless bees (Stangler et al. 2009), which contain carboxylic and terpene esters. Octyl hexanoate, octyl octanoate, hexyl decanoate, octyl decanoate, and decyl hexanoate are shared with other species (Jarau 2009; Jarau et al. 2010), while hexyl octanoate is reported for the first time as components of stingless bee recruitment pheromones. Behavior of other Trigona species suggests that foragers require the entire blend of chemicals to exhibit natural trail-following behavior (Jarau 2009). Interestingly, the esters found in T. hyalinata recruitment pheromone are also found in other glandular extracts thought to have an attractive function. These include the Dufour's gland in Andrena (Fernandes et al. 1981; Hefetz 1987), Dufourea (Wheeler et al. 1985), and Svastra (Duffield et al. 1984) bee species, and mandibular and preputial glands that likely produce sex pheromones in several Myrmecocystus ant species (Lloyd et al. 1989) and the Brandt's vole (Zhang et al. 2007), respectively.
Table 3 Major compounds in Trigona hyalinata labial gland secretions, determined by GC-MS and comparison with analytical standards

Retention times are for the DB-WAX column

\begin{tabular}{lllc}
\hline Peak & Compound & Retention time (min) & Relative abundance (\%) \\
\hline A & hexyl octanoate & 29.374 & 13.06 \\
B & octyl hexanoate & 29.425 & 1.92 \\
C & octyl octanoate & 36.180 & 45.46 \\
D & hexyl decanoate & 36.249 & 12.64 \\
E & decyl hexanoate & 36.329 & 13.33 \\
F & octyl decanoate & 42.460 & 13.59 \\
\hline
\end{tabular}




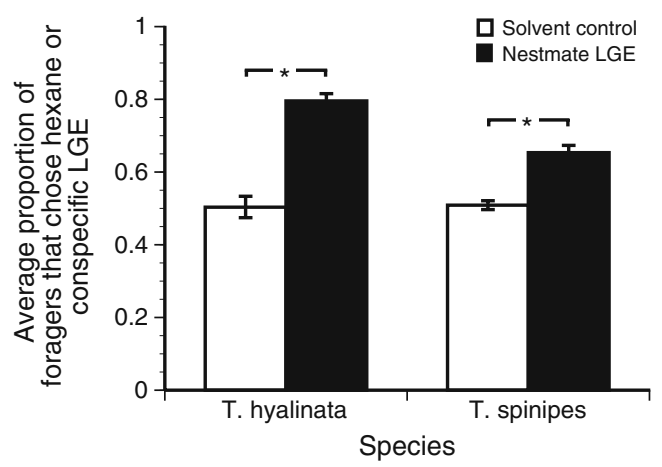

Fig. 3 Responses of T. hyalinata and T. spinipes foragers to labial gland extract (LGE) from nestmates in intraspecific preference tests, compared to responses to hexane in solvent control trials (question A1). Bars show the average proportion of foragers preferring the given odor $( \pm \mathrm{SE})$. Asterisks indicate statistically significant differences $(\alpha=0.05)$

In intraspecific preference tests, $T$. spinipes showed weaker preference $(65 \%)$ than did $T$. hyalinata $(80 \%)$. Trigona spinipes preferences were also weaker than in other preference experiments (73\%, Nieh et al. 2004b; $90 \%$, Schorkopf et al. 2007), while T. hyalinata shows greater consistency across studies ( $81 \%$, Nieh et al. 2003). Three major differences in life history traits between these species could be related to this, although the last two seem less likely. First, $T$. spinipes appear to be highly generalist in their floral visitation, visiting $51 \%$ of 562 plant species for

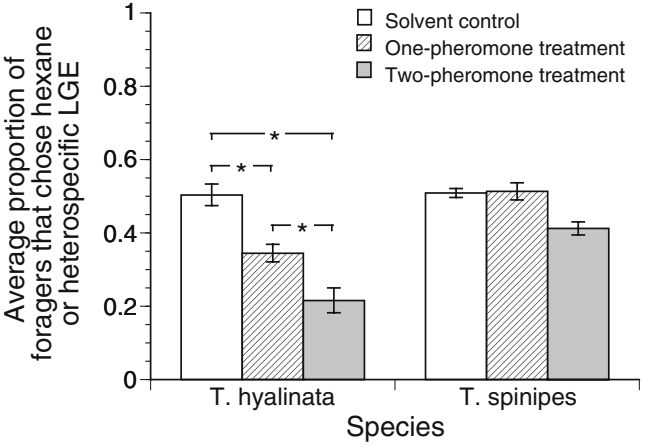

Fig. 4 Interspecific eavesdropping analysis (question A4), comparing preferences for hexane in solvent control trials with heterospecific LGE in the absence ("One-pheromone treatment") and presence ("Two-pheromone treatment") of nestmate LGE. Bars show the average proportion of foragers preferring the given odor $( \pm \mathrm{SE})$. Asterisks indicate statistically significant differences $(\alpha=0.05)$

which we have collated stingless bee resource use data. Trigona hyalinata, however, were found on only $5 \%$ of the plants and seem to specialize on dense floral patches: trees and shrubs (unpublished data). The relationship between floral preference patterns and reliance on social information is not clear and bears further investigation. Second, at the species level T. hyalinata are more dominant and aggressive than T. spinipes (Lichtenberg et al. 2010). Third, T. hyalinata colonies have almost three times the number of workers as $T$. spinipes colonies have (D.W. Roubik,
Table 4 ANOVA results for recruitment pheromone glandular source and heterospecific eavesdropping questions asked in the "Data analysis" subsection of the "Materials and methods" section, separated by responding species

All interactions were not significant, and were removed from analyses. All analyses in this table used LGE. Statistics for questions A2 and A3 are given in the text

\begin{tabular}{lccc} 
Research question & \multicolumn{2}{c}{ ANOVA output } & \\
\cline { 2 - 4 } Effect & $F$ & $p$ & $d f$ \\
\hline Trigona hyalinata & & \\
(A1) Recruitment pheromone glandular source & & \\
Trial type & 67.28 & $<0.0001$ & 1,18 \\
Colony & 1.03 & 0.32 & 18 \\
(A4) Eavesdropping on heterospecific recruitment pheromone & 2,30 \\
Trial type & 20.01 & $<0.0001$ & 1,30 \\
Colony & 1.66 & 0.21 &
\end{tabular}

(A5) Response to own recruitment pheromone in the presence or absence of heterospecific pheromone

$\begin{array}{llll}\text { Trial type } & 0.003 & 0.96 & 1,19 \\ \text { Colony } & 2.62 & 0.12 & 1,19\end{array}$

Trigona spinipes

(A1) Recruitment pheromone glandular source

$\begin{array}{lccc}\text { Trial type } & 37.23 & <0.0001 & 1,15 \\ \text { Colony } & 1.54 & 0.23 & 1,15 \\ \text { (A4) Eavesdropping on heterospecific recruitment pheromone } & \\ \text { Trial type } & 3.19 & 0.06 & 2,29 \\ \text { Colony } & 0.08 & 0.78 & 1,29\end{array}$

(A5) Response to own recruitment pheromone in the presence or absence of heterospecific pheromone

$\begin{array}{lcll}\text { Trial type } & 12.57 & 0.002 & 1,17 \\ \text { Colony } & 0.004 & 0.95 & 1,17\end{array}$




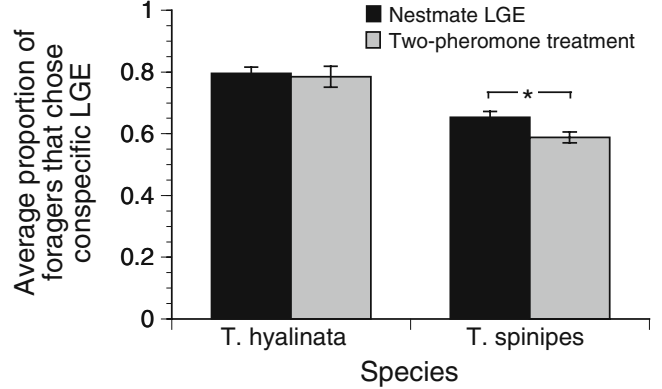

Fig. 5 Responses to nestmate LGE in the absence ("Nestmate LGE") and presence ("Two-pheromone treatment") of heterospecific LGE (question A5). Bars show the average proportion of foragers preferring the given odor $( \pm \mathrm{SE})$. Asterisks indicate statistically significant differences $(\alpha=0.05)$

personal communication; Wille and Michener 1973). This is likely related to the dominant status of T. hyalinata; species with larger colonies tend to be more dominant (Lichtenberg et al. 2010). It is unlikely that species' dominance affects degree of reliance on information provided by nestmates, since subordinate Melipona species show strong attraction to nestmates' chemical "footprints" (e.g., 91\%; Nieh 1998).

Most previous research on stingless bee recruitment pheromones utilized artificial trails rather than presenting odors at a food source (the feeder), as we did. This raises the possibility that pheromones deposited at the food source differ from those used in odor trails. However, no evidence indicates that stingless bees have two separate recruitment pheromones. Our protocol used the same pheromoneproducing gland as artificial trail studies. In one case, chemically analyzed odor marks were collected from the feeder (Schorkopf et al. 2007). In addition, T. spinipes and T. hyalinata create polarized odor trails, depositing the majority of their pheromone within $1 \mathrm{~m}$ of the feeder (Nieh et al. 2004b). Because the trail is an extension of odor marks at the food source, it is reasonable to assume that pheromone deposited on the feeder is the same as trail pheromone, and that the bees obtain the same meaning from our experimental setup and odor trails.

The pheromone concentration that we used, 0.1 bee equivalents, elicited a natural response in a congener, Trigona recursa (Jarau et al. 2004), and in our experiments. Eavesdropping responses of $T$. hyalinata and $T$. spinipes were the same whether the treatment was fresh pheromone that had elicited strong natural recruitment or LGE ( $T$. hyalinata, $29 \%$ vs. $34 \%$ of bees choosing the feeder with pheromone; T. spinipes, $52 \%$ vs. $51 \%$ ). Each species also showed a highly significant $(p<0.0001)$ preference for nestmate recruitment pheromone at 0.1 bee equivalents (Fig. 3; T. hyalinata, $80 \%$ choosing the feeder with pheromone; T. spinipes, 65\%). The strength of these preferences was similar to those shown by each species in preference tests that employed odor trails (Nieh et al. 2003; Nieh et al. 2004b). Greater or lesser amounts of LGE may elicit different eavesdropping responses than those reported here. Predatory ants eavesdropping on fig volatiles exhibit such a dose-dependent response, showing greater attraction to larger quantities of figs (Ranganathan and Borges 2009). However, our results show that 0.1 bee equivalents are sufficient to elicit both conspecific and heterospecific responses that are the same as responses to natural-deposited pheromone at approximately the same concentration.

\section{Interspecific eavesdropping}

The limited amount of natural habitat near the laboratory and Trigona preferences for nesting high in trees limited the number of colonies that we were able to work with. Despite this, we feel that our results reflect species-typical behaviors. Results were highly consistent across replicate colonies (Table 4), and each colony showed the same response to pheromone from two different heterospecific colonies (A3). This consistency across colonies and months also indicates that a species' eavesdropping behavior does not vary much, if at all, with the current food needs of the colony.

Trigona spinipes foragers clearly could detect the presence of heterospecific pheromone. Preference for nestmate pheromone decreased significantly, albeit slightly (Fig. 5; going from $65 \%$ to $59 \%$ choosing the T. spinipes LGE; $p=0.002$ ), when bees chose between conspecific and heterospecific pheromones. Thus, T. spinipes does recognize T. hyalinata pheromone as different. Despite this detection ability, $T$. spinipes foragers exhibited a behavioral lack of choosiness in eavesdropping tests, showing no preference between feeders with no odor and T. hyalinata pheromone (Fig. 4). A similar failure to use social information has been found for three-spined sticklebacks, although the related nine-spined sticklebacks use similar social information (Coolen et al. 2003). Trigona spinipes are attracted to footprint cues of the subordinate Melipona rufiventris at certain locations (Nieh et al. 2004a), suggesting they have a species- and context-specific response to social information, and heterospecific signals and cues do not always alter their movements. Bumble bees also facultatively use social information, exhibiting visual local enhancement only when approaching unfamiliar flower types (Kawaguchi et al. 2007). Alternately, T. spinipes may ignore $T$. hyalinata pheromones when they cannot also see foragers on the marked food source. Apis mellifera ignore olfactory information when sufficient visual information is available (Giurfa et al. 1994).

Contrary to our expectation, T. hyalinata foragers showed strong avoidance of the subordinate species' recruitment pheromone (Fig. 4). This result was surprising, 
given previous patterns of social information use by social insects (Slaa and Hughes 2009) and the highly dominant behavior exhibited by $T$. hyalinata (Lichtenberg et al. 2010). It is unlikely that our results reflect avoidance of all non-nestmate recruitment pheromones by $T$. hyalinata foragers. Individual $T$. hyalinata foragers will fly to and attack other species at food sources (Lichtenberg et al. 2010). Given that dominant stingless bee species such as $T$. hyalinata appear to be relatively poor at discovering new food sources (the dominance-discovery trade-off, Fellers 1987; Nagamitsu and Inoue 1997), avoiding all nonnestmate odors would severely limit food intake by $T$. hyalinata colonies.

Our findings are consistent with a hypothesis of conflict avoidance through eavesdropping decisions. Attacking to gain control of an occupied resource can inflict mortality losses even for highly dominant species (Johnson and Hubbell 1974; Nieh et al. 2005). The recruitment pheromone we presented to eavesdropping T. hyalinata in trials with fresh odor marks and LGE corresponds to the presence of numerous subordinate foragers. In our fresh odor mark trials, we collected marks once a "pulse" (Nieh et al. 2004b) of at least 30 bees arrived at the feeder. Stingless bee trails must be actively maintained by bees interrupting their food collection, and begin to fade out after approximately $20 \mathrm{~min}$ without such maintenance. Thus, recruitment pheromones provide current information on both resource availability and abundance of bees already present at the resource. Under such conditions, attack may be costly for a $T$. hyalinata colony because it may require the participation of hundreds of bees, which could otherwise be recruited to non-contested food sources. Trigona hyalinata foragers' decisions to not choose a resource at which social information predicts high numbers of subordinate heterospecifics may be similar to the failure of dominant Trigona silvestriana to drive away large numbers of subordinate bees (Johnson and Hubbell 1974). Indeed, while $T$. hyalinata can easily displace a group of foraging $T$. spinipes, they do not attempt to do so every time they encounter the subordinate species (personal observation). This behavior merits further study. One possible explanation is that social insect eavesdropping decisions include expected costs associated with each choice; research that we are currently conducting investigates this.

Different lines of evidence suggest that eavesdropping on signals and spying on cues affect the movements of social bees. First, we have observed T. hyalinata depositing odor marks on flowers. Second, feeders are discovered more quickly by other stingless bee species when they bear recruitment pheromone or a large quantity of footprints (Johnson 1983). Finally, interspecific interactions increase between-plant movement of honey bees (Greenleaf and Kremen 2006) and bumble bees (Kawaguchi et al. 2007), and may do the same for eavesdropping stingless bees. Our results indicate that social information use by competitors is governed by complex rules. Potentially large ecological and evolutionary impacts make this an important area for future investigation.

Acknowledgments We thank Angie Kemsley for field assistance; Ronaldo Zucchi and Sidnei Mateus for lab space and equipment; Ian Abramson for statistical advice; Jocelyn Millar and Steve McElfresh for chemical techniques guidance; and Eben Goodale, Erin Wilson and anonymous reviewers for their insightful comments. Jocelyn Millar and Stefan Jarau kindly provided analytical standards. This research was funded by a UCSD Chancellor's Fellowship (EML), a NSF Graduate Research Fellowship (EML), a UCSD Division of Biological Sciences travel award (EML), the Animal Behavior Society (EML), FAPESP 06/50809-7 (MH), and NSF IBN 0545856 (JCN). These experiments comply with current laws in Brazil and the United States.

Conflict of interest The authors declare that they have no conflict of interest.

Open Access This article is distributed under the terms of the Creative Commons Attribution Noncommercial License which permits any noncommercial use, distribution, and reproduction in any medium, provided the original author(s) and source are credited.

\section{References}

Biesmeijer JC, de Vries H (2001) Exploration and exploitation of food sources by social insect colonies: a revision of the scout-recruit concept. Behav Ecol Sociobiol 49:89-99

Boogert NJ, Hofstede FE, Aguilar Monge I (2006) The use of food source scent marks by the stingless bee Trigona corvina (Hymenoptera: Apidae): the importance of the depositor's identity. Apidologie 37:366-375

Camargo JMF, Pedro SRM (2007) Meliponini Lepeletier, 1836. In: Moure JS, Urban D, Melo GAR (eds) Catalogue of bees (Hymenoptera, Apoidea) in the Neotropical region. Sociedade Brasileira de Entomologia, Curitiba, pp 272-578

Coolen I, van Bergen Y, Day RL, Laland KN (2003) Species difference in adaptive use of public information in sticklebacks. Proc R Soc B 270:2413-2419

Dall SRX, Giraldeau L-A, Olsson O, McNamara JM, Stephens DW (2005) Information and its use by animals in evolutionary ecology. Trends Ecol Evol 20:187-193

Danchin É, Giraldeau L-A, Valone TJ, Wagner RH (2004) Public information: from nosy neighbors to cultural evolution. Science 305:487-491

Dornhaus A, Chittka L (2004) Why do honey bees dance? Behav Ecol Sociobiol 55:395-401

Duffield RM, LaBerge WE, Wheeler JW (1984) Exocrine secretions of bees-VII. Aliphatic esters in the Dufour's gland secretion of Svastra obliqua obliqua (Hymenoptera: Anthophoridae). Comp Biochem Physiol 78B:47-50

Dukas R (2008) Evolutionary biology of insect learning. Annu Rev Entomol 53:145-160

Eltz T, Brühl CA, van der Kaars S, Linsenmair KE (2002) Determinants of stingless bee nest density in lowland dipterocarp forests of Sabah, Malaysia. Oecologia 131:27-34 
Endress PK (1994) Diversity and evolutionary biology of tropical flowers. Cambridge University Press, Cambridge

Evans TA, Inta R, Lai JCS, Prueger S, Foo NW, EWe Fu, Lenz M (2009) Termites eavesdrop to avoid competitors. Proc R Soc B 276:4035-4041

Fellers JH (1987) Interference and exploitation in a guild of woodland ants. Ecology 68:1466-1478

Fernandes A, Duffield RM, Wheeler JW, LaBerge WE (1981) Chemistry of the Dufour's gland secretions of North American andrenid bees (Hymenoptera: Andrenidae). J Chem Ecol 7:453-463

Fletcher RJ (2008) Social information and community dynamics: nontarget effects from simulating social cues for management. Ecol Appl 18:1764-1773

Giraldeau L-A (1997) The ecology of information use. In: Krebs JR, Davies NB (eds) Behavioural Ecology, 4th edn. Blackwell Science, Cambridge, pp 42-68

Giurfa M, Núñez J, Backhaus W (1994) Odour and colour information in the foraging choice behaviour of the honeybee. J Comp Physiol A 175:773-779

Goodale E, Beauchamp G, Magrath RD, Nieh JC, Ruxton GD (2010) Interspecific information transfer influences animal community structure. Trends Ecol Evol 25(6):354-361

Goulson D (2009) The use of scent marks by foraging bumble bees. In: Jarau S, Hrncir M (eds) Food Exploitation by Social Insects: Ecological, Behavioral, and Theoretical Approaches. CRC, Boca Raton, pp 251-260

Greenfield MD (2002) Signalers and receivers: mechanisms and evolution of arthropod communication. Oxford University Press, New York

Greenleaf SS, Kremen C (2006) Wild bees enhance honey bees' pollination of hybrid sunflower. Proc Natl Acad Sci USA 103:13890-13895

Hefetz A (1987) The role of Dufour's gland secretions in bees. Physiol Entomol 12:243-253

Hölldobler B, Wilson EO (1990) The Ants. Belknap Press of Harvard University Press, Cambridge

Hubbell SP, Johnson LK (1977) Competition and nest spacing in a tropical stingless bee community. Ecology 58:949-963

Jarau S (2009) Chemical communication during food exploitation in stingless bees. In: Jarau S, Hrncir M (eds) Food exploitation by social insects: ecological, behavioral, and theoretical approaches. CRC, Boca Raton, pp 223-249

Jarau S, Dambacher J, Twele R, Aguilar I, Francke W, Ayasse M (2010) The trail pheromone of a stingless bee, Trigona corvina (Hymenoptera, Apidae, Meliponini), varies between populations. Chem Senses 35(7):593-601

Jarau S, Hrncir M, Zucchi R, Barth FG (2004) A stingless bee uses labial gland secretions for scent trail communication (Trigona recursa Smith 1863). J Comp Physiol A 190:233-239

Johnson LK (1983) Foraging strategies and the structure of stingless bee communities in Costa Rica. In: Jaisson P (ed) Social insects in the tropics: proceedings of the first international symposium organized by the International Union for the Study of Social Insects and the Sociedad Mexicana de Entomología. Université Paris-Nord, Morelos, pp 31-58

Johnson LK, Hubbell SP (1974) Aggression and competition among stingless bees: field studies. Ecology 55:120-127

Johnson LK, Hubbell SP (1975) Contrasting foraging strategies and coexistence of two bee species on a single resource. Ecology 56:1398-1406

Kawaguchi LG, Ohashi K, Toquenaga Y (2007) Contrasting responses of bumble bees to feeding conspecifics on their familiar and unfamiliar flowers. Proc R Soc B 274:2661-2667

Kean J, Wratten S, Tylianakis J, Barlow N (2003) The population consequences of natural enemy enhancement, and implications for conservation biological control. Ecol Lett 6:604-612
Kerr WE (1959) Bionomy of meliponids-VI-Aspects of food gathering and processing in some stingless bees. In: University $\mathrm{C}$ (ed) Symposium on food gathering behavior of hymenoptera. Ithaca, NY, pp 2-4

Kerr WE, Ferreira A, Simões de Mattos N (1963) Communication among stingless bees — additional data (Hymenoptera: Apidae). J New York Entomol S 71:80-90

Lichtenberg EM, Imperatriz-Fonseca VL, Nieh JC (2010) Behavioral suites mediate group-level foraging dynamics in communities of tropical stingless bees. Insect Soc 57:105-113

Lloyd HA, Blum MS, Snelling RR, Evans SL (1989) Chemistry of mandibular and Dufour's gland secretions of ants in genus Myrmecocystus. J Chem Ecol 15:2589-2599

Maynard Smith J, Harper D (2003) Animal signals. Oxford University Press, New York

Mclafferty J (2000) Wiley registry of mass spectral data, 7th edn. Wiley, Hoboken

Nagamitsu T, Inoue T (1997) Aggressive foraging of social bees as a mechanism of floral resource partitioning in an Asian tropical rainforest. Oecologia 110:432-439

Nakashima Y, Teshiba M, Hirose Y (2002) Flexible use of patch marks in an insect predator: effect of sex, hunger state, and patch quality. Ecol Entomol 27:581-587

Nieh JC (1998) The role of a scent beacon in the communication of food location in the stingless bee, Melipona panamica. Behav Ecol Sociobiol 43:47-58

Nieh JC (2004) Recruitment communication in stingless bees (Hymenoptera, Apidae, Meliponini). Apidologie 35:159-182

Nieh JC, Barreto LS, Contrera FAL, Imperatriz-Fonseca VL (2004a) Olfactory eavesdropping by a competitively foraging stingless bee, Trigona spinipes. Proc R Soc B 271:1633-1640

Nieh JC, Contrera FAL, Nogueira-Neto P (2003) Pulsed massrecruitment by a stingless bee, Trigona hyalinata. Proc R Soc B 270:2191-2196

Nieh JC, Contrera FAL, Yoon RR, Barreto LS, Imperatriz-Fonseca VL (2004b) Polarized short odor-trail recruitment communication by a stingless bee, Trigona spinipes. Behav Ecol Sociobiol 56:435-448

Nieh JC, Kruizinga K, Contrera FAL, Barreto LS, Imperatriz-Fonseca VL (2005) Effect of group size on the aggression strategy of an extirpating stingless bee, Trigona spinipes. Insect Soc 52:147-154

Peake TM (2005) Eavesdropping in communication networks. In: McGregor PK (ed) Animal communication networks. Cambridge University Press, Cambridge, pp 13-37

Pimm SL, Rosenweig ML, Mitchell W (1985) Competition and food selection: field tests of a theory. Ecology 66:798-807

Ranganathan Y, Borges RM (2009) Predatory and trophobiont-tending ants respond differently to fig and fig wasp volatiles. Anim Behav 77:1539-1545

Roubik DW, Yanega D, Aluja SM, Buchmann SL, Inouye DW (1995) On optimal nectar foraging by some tropical bees (Hymenoptera: Apidae). Apidologie 26:197-211

Schorkopf DLP, Jarau S, Francke W, Twele R, Zucchi R, Hrncir M, Schmidt VM, Ayasse M, Barth FG (2007) Spitting out information: Trigona bees deposit saliva to signal resource location. Proc R Soc B 274:895-898

Seppänen J-T, Forsman JT, Mönkkönen M, Thomson RL (2007) Social information use is a process across time, space, and ecology, reaching heterospecifics. Ecology 88:1622-1633

Slaa EJ, Hughes WOH (2009) Local enhancement, local inhibition, eavesdropping, and the parasitism of social insect communities. In: Jarau S, Hrncir M (eds) Food exploitation by social insects: ecological, behavioral, and theoretical approaches. CRC, Boca Raton, pp 147-164

Slaa EJ, Wassenberg J, Biesmeijer JC (2003) The use of field-based social information in eusocial foragers: local enhancement among nestmates and heterospecifics in stingless bees. Ecol Entomol 28:369-379 
Stangler ES, Jarau S, Hrncir M, Zucchi R, Ayasse M (2009) Identification of trail pheromone compounds from the labial glands of the stingless bee Geotrigona mombuca. Chemoecology 19:13-19

Stevens JR, Gilby IC (2004) A conceptual framework for nonkin food sharing: timing and currency of benefits. Anim Behav 67:603-614

Stout JC, Goulson D, Allen JA (1998) Repellent scent-marking of flowers by a guild of foraging bumblebees (Bombus spp.). Behav Ecol Sociobiol 43:317-326

Stowe MK, Turlings TCJ, Loughrin JH, Lewis WJ, Tumlinson JH (1995) The chemistry of eavesdropping, alarm, and deceit. Proc Natl Acad Sci USA 92:23-28

Valone TJ (2007) From eavesdropping on performance to copying the behavior of others: a review of public information use. Behav Ecol Sociobiol 62:1-14

von Frisch K (1967) The dance language and orientation of bees, 2nd printing, 1993rd edn. Belknap, Cambridge

Wheeler JW, Shamim MT, Ekpa O, Eickwort GC, Duffield RM (1985) Exocrine secretions of bees. VI. Unsaturated ketones and aliphatic esters in the Dufour's gland secretion of Dufourea novaeangliae (Hymenoptera: Halictidae). J Chem Ecol 11:353-361

Wille A, Michener CD (1973) The nest architecture of stingless bees with special reference to those of Costa Rica (Hymenoptera: Apidae). Rev Biol Trop 21:1-278

Wisenden BD, Stacey NE (2005) Fish semiochemicals and the evolution of communication networks. In: McGregor P (ed) Animal communication networks. Cambridge University Press, Cambridge, pp 540-567

Yokoi T, Goulson D, Fujisaki K (2007) The use of heterospecific scent marks by the sweat bee Halictus aerarius. Naturwissenschaften 94:1021-1024

Zar JH (1999) Biostatistical analysis, 4th edn. Prentice-Hall, Inc., Upper Saddle River

Zhang J-X, Zhao C-H, Rao X-P, Wang D-W, Liu X-H, Qin X-W, Zhang Z-B (2007) Gender and individual information coded by insect pheromone analogs in the preputial glands in male brandt's voles Lasiopodomys brandtii. Acta Zool Sinica $53: 616-624$ 